\title{
Yangının Toprakların Bazı Makro ve Mikro Besin Elementleri Üzerine Etkilerinin Araştırılması
}

\author{
Şahin PALTA ${ }^{1 *}$ \\ ${ }^{1}$ Bartın Üniversitesi, Orman Fakültesi, Orman Mühendisliği Bölümü,74100, Bartın
}

Öz

Makro ve mikro bitki besin elementleri bitkilerin büyümesi ve gelişmesi için oldukça önemli olan kimyasal toprak karakteristiklerindendir. Bitki besin elementlerinin bir kısmı bitkiler için hayati önem taşırken bazıları ise bitkilerin daha iyi gelişmesine yardımcı olmaktadır. Bu çalışma Bartın İli, Arıt Beldesi, Darı̈ren mevkiinde yürütülmüştür. Araştırma alanında bulunan bir sekonder mera alanında 29 Ağustos 2020 tarihinde yangın meydana gelmiştir. Yangının toprakların fiziksel, kimyasal ve biyolojik özellikleri üzerinde etkilerinin olduğu bilinmektedir. Bu araştırmanın amacı yangından kısa süre sonra toprakların bazı makro ve mikro besin elementleri üzerinde meydana gelen değişikliklerin araştırılmasıdır. Bu amaçla belirtilen yangın tarihinden bir ay sonra araziye çıkılmıştır. Arazide karşılaştırma yapabilmek amacıyla yanmış sekonder mera alanı, yanmamış sekonder mera alanı ve yanmamış tarım alanı olmak üzere üç tip çalışma alanı belirlenmiştir. Her çalışma alanından 10'ar tane toprak örneği alınmıştır. Alınan toprak örneklerinde makro besin elementlerinden kalsiyum ve magnezyum; mikro besin elementlerinden sodyum, demir, bakır, çinko ve mangan analiz edilmiştir. Çalışma sonuçlarına göre; yangının bazı besin elementleri üzerinde istatistiki anlamda farklılıklar oluşturduğu belirlenmiştir. Yangın sahasında, kalsiyum, demir, bakır ve mangan içeriklerinin yanmamış alana kıyasla artmış olduğu tespit edilmiştir. Yangının magnezyum ve sodyum içeriklerini istatistiki anlamda düşürdüğü bulunmuştur. Ancak, toprakların çinko içeriklerinde istatistiki anlamda bir fark bulunamamıştır.

Anahtar Kelimeler: Sekonder mera, yangın, makro besin elementleri, mikro besin elementleri.

\section{Investigation of the Effects of Wildfire on Some Macro and Micro Nutritional Elements of Soil}

\begin{abstract}
Macro and micro plant nutrients are very important chemical soil characteristics for the growth and development of plants. Some of the plant nutrients are vital for plants, while others help plants to develop better. This study was carried out Arıt Town, Darıören locality in Bartın Province, the fire occurred in the secondary pasture area on 29 August 2020. It is known that fire has effects on physical, chemical and biological properties of soils. The aim of this research is to investigate the changes that occur on some macro and micro nutrients of soils shortly after the fire. For this purpose, the field work was carried out exactly one month after the fire. In order to make a comparison in the field, three types of work areas have been determined: burnt secondary pasture area, unburned secondary pasture area and unburned agricultural area. 10 soil samples were taken from each study area. Calcium and magnesium from macro nutrients; sodium, iron, copper, zinc and manganese from micro nutrients were analyzed. According to the results of the study; the nutrients were statistically significant depending on the wildfire. It was determined that the contents of calcium, iron, copper and manganese in the wildfire area increased compared to the unburned area. It was found that the wildfire decreased the magnesium and sodium contents statistically. However, the zinc content of the soils was non-significant.
\end{abstract}

Keywords: Secondary pasture, wildfire, macro nutrients, micro nutrients. 


\section{Giriş}

Yangın Türkiye'nin farklı bölgelerinde her yıl görülebilen doğal afetlerin başında gelmektedir. Yangınlar bazen hektarlarca ormanı yok ederken bazen oldukça verimli alanların kaybolmasına neden olmaktadır. Yangın etkisi ile vejetasyonun ortadan kalkmasına bağlı olarak, özellikle eğimli arazilerde erozyon ile toprak kayıpları başlamaktadır. Uzun yıllar sonunda klimaks vejetasyona sahip olan araziler bazen yangının etkisi ile çok kısa sürede bitki örtüsünü kaybetmektedir. Böylece primer süksesyon ile çok uzun yıllar sonucunda oluşan klimaks vejetasyon ortadan kalkmakta ve sekonder süksesyon başlamaktadır. Ancak sekonder süksesyon sürecinde, yeniden klimaks vejetasyonun oluşması uzun zaman almaktadır. Sekonder süksesyon ile alana öncelikle tek yıllık bitkilerin gelmesi ve bu bitkilerin toprağı koruması oldukça zaman almaktadır. Bu süreçte yağmur sularının darbe etkisi ve yüzeysel akış ile eğimli arazilerde erozyon riski artmaktadır. Toprak erozyonu ile verimli üst toprak kaybedilerek eğim yönünde alt yamaçlara taşınmaktadır.

Yangınların; toprağın yapısını, fiziko-kimyasal özelliklerini, bitki besin maddesi seviyelerini, mikrobiyal biyomasını ve vejetasyon özelliklerini değiştirerek toprakların biyotik ve abiyotik karakteristiklerini önemli ölçüde değiştirebildikleri ifade edilmiştir (Diaz-Fierros vd., 1989; White vd., 1973; St Jhon ve Rundel, 1976; Hernandez vd., 1997; Chandler vd., 1983; Carballas vd., 1993; Vazquez vd., 1993; Vazquez vd., 1996; Guerrero vd. 2001). Yangın sonrası topraklarda meydana gelen biyotik ve abiyotik değişimlerin şiddetinin yangının sıklığ ve yoğunluğu ile ilişkili olduğu belirtilmiştir (Kutiel ve Shaviv, 1989).

Yangınlar, buharlaşma ve sonrasında sedimentasyona bağlı olarak topraktaki besin maddelerinin azalmasına neden olmaktadır (Certini, 2005; Neary vd., 2005). Ancak, organik maddenin yanması nedeniyle suda çözünen formlardaki besin maddelerinin açığa çıkması ile elde edilebilir besin maddelerinin artmasına neden olmaktadır (Brais vd., 2000; Murphy vd., 2006a).

Yangının vejetasyon örtüsünü tahrip ettiği, toprak kayıpları ve bitki besin maddelerinin kaybedilmesine bağlı olarak toprakların verimsizleşmesine neden olduğu ifade edilmiştir (Fernandez vd., 2007; Kara ve Bolat, 2009). Kalsiyum ve magnezyumun buharlaşma sıcaklıkları oldukça yüksek olduğundan genellikle yangın sonrasında topraktan kaybolmamaktadır (Neary vd., 2005).

Yangın ile bitki besin maddeleri serbest kalmaktadır. Ayrıca yangına bağlı olarak bitki besin maddelerinin alınabilirliği artabildiği gibi aynı zamanda azalabilmektedir. Yangın geçirmiş bir alanda topoğrafya, ölü örtü, diri örtü ve toprak tipi bitki besin maddeleri üzerinde etkili olmaktadır (Caon vd., 2014; Parlak, 2018).

Makro ve mikro bitki besin maddeleri bitkilerin büyümesi ve gelişmesinde oldukça önemli bir yere sahiptir. Bunların bazıları hayati öneme sahip iken bazıları bitkilerin daha sağlıklı bir gelişim gösterebilmesi için gereklidir (Bolat vd., 2020).

Tropikal ormanlarda hafif ve şiddetli kontrollü yangınların toprak karakteristiklerine etkileri araştırılmıştır. Araştırma sonuçlarına göre; hafif ve şiddetli yangınların her ikisinde de diğer uygulamalara kıyasla $\mathrm{P}, \mathrm{K}, \mathrm{Mg}, \mathrm{Ca}$ ve pH'nın istatistiki anlamda arttığı ancak bu artışın hafif şiddetteki yangın sahasında, şiddettli yangın sahasına kıyasla daha düşük olduğu belirtilmiştir (Kennard ve Gholz 2001). Yangının şiddetlenmesine bağlı olarak üst topraktaki Ca miktarının azaldığı ancak K ve Mg içeriğinin arttığı belirtilmiştir (Badia ve Marti 2003).

Bartın ilinde karaçam ormanlarında meydana gelen yangının toprak özelliklerine etkilerini araştırmak amacıyla yangından iki ay sonra alınan toprak nümuneleri analiz edilmiştir. Çalışma sonuçlarına göre yangının toprakların bazı kimyasal özelliklerini artırdığı belirtilmiştir (Kara ve Bolat, 2009).

Topografya, yangın şiddeti ve toprak karakteristiklerinin hepsinin yangın sonrasında, toprakta besin elementleri kompozisyonunun şekillenmesinde çok önemli olduğu belirtilmiştir (Griffiths vd., 2009; Turner vd., 2011). Ayrıca, topografya; yanıcı madde türü, nemi ve bitki örtüsü biyokütlesinin mekansal dağılımı yangının yayılma davranışını etkileyebilmektedir (Fang vd., 2015).

Yangınların zamana bağlı olarak toprak besin elementleri üzerindeki etkilerinin daha iyi anlaşılabilmesi için; yangın sonrası kısa dönem ve uzun dönem toprak analizlerinin yapıldığı daha fazla çalışmaya ihtiyaç duyulmaktadır (Kong vd., 2018).

Türkiye'de ve dünyada orman yangınlarının toprakların makro ve mikro besin elementleri üzerine etkilerinin araştırıldığı sınırlı sayıda çalışma olmakla birlikte, mera alanlarında meydana gelen yangınların mera toprakları üzerine etkileri konusundaki araştırma sayısı oldukça azdır. Bu araştırmanın amacı, sekonder mera alanında 
meydana gelen yangından kısa süre sonra (bir ay) toprakların bazı makro ve mikro besin elementleri üzerinde meydana gelen değişikliklerin araştırılmasıdır.

\section{Materyal ve Metot}

\subsection{Materyal}

Çalışma Bartın İli, Arıt Beldesi, Darı̈ren mevkiinde bulunan ve 29 Ağustos 2020 tarihinde yanan sekonder mera alanında yürütülmüştür (Şekil 1).

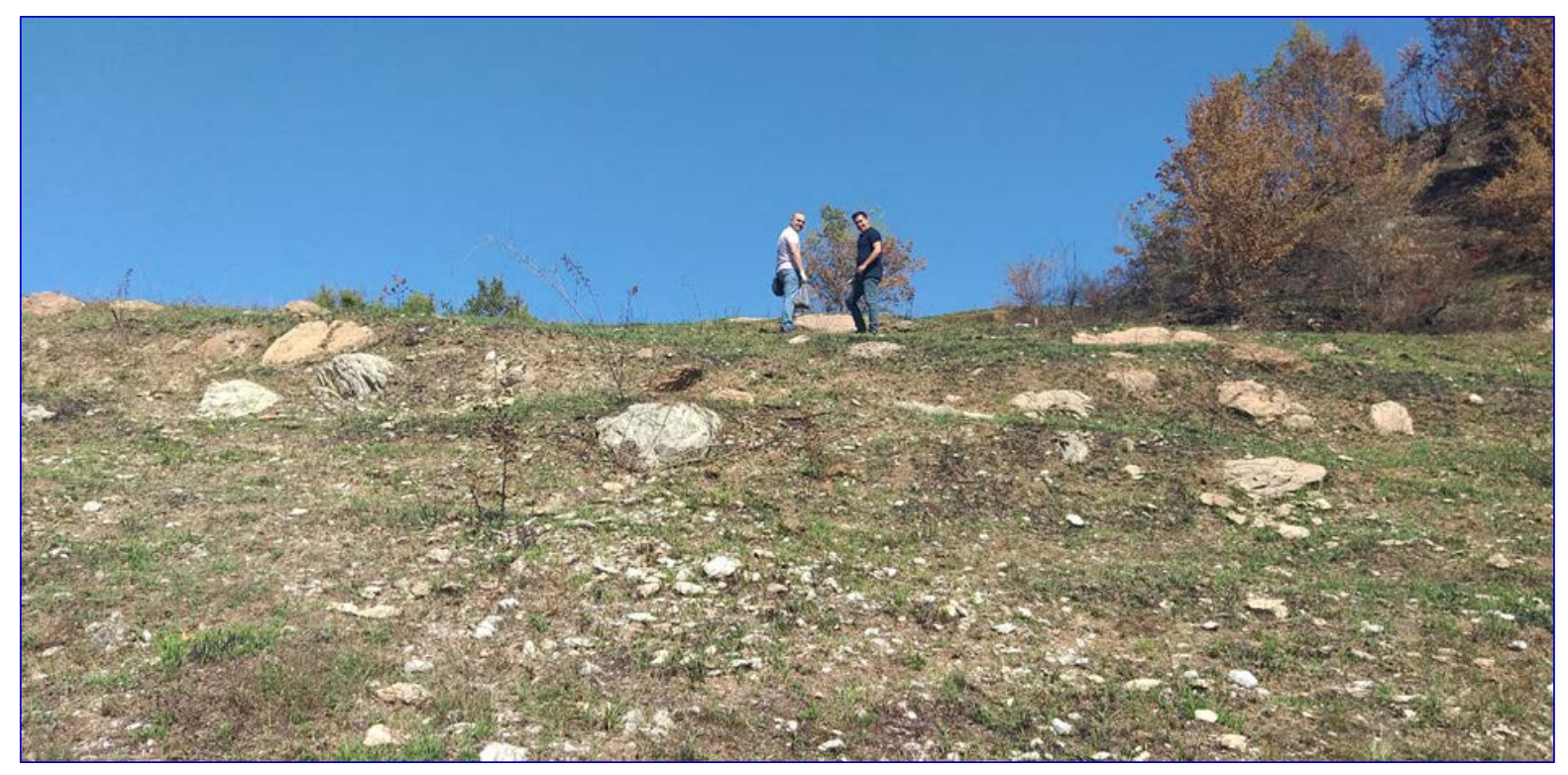

Şekil 1. Yangın sahasından bir görünüş.

Arıt Beldesi’nin Tornthwaite metoduna göre ikliminin; çok nemli, mezotermal, yağış rejimine göre su açığı olmayan veya pek az olan ve deniz iklimi altında (AB1'rb3') bulunan bir iklim olduğu belirtilmiştir. Arıt Beldesinin yıllık ortalama sıcaklığının $8.8^{\circ} \mathrm{C}$, en soğuk ayının ocak ayı ve en sıcak ayının ise temmuz ayı olduğu ifade edilmiştir. Arıt Beldesinin yıllık toplam yağışının $1431.4 \mathrm{~mm}$ olduğu, en az yağış alan ayların nisan ve mayıs olduğu, en fazla yağışın ise aralık ayında düştüğü bildirilmiştir (Bolat vd., 2020).

\subsection{Metot}

Yangın tarihinden tam bir ay sonra araziye çıkılmıştır. Arazide karşılaştırma yapabilmek amacıyla yanmış sekonder mera alanı, yanmamış sekonder mera alanı ve yanmamış tarım alanı olmak üzere üç tip çalışma alanı belirlenmiştir. Her çalışma alanından 0-15 cm derinlikten 10'ar tane toprak örneği alınmıştır. Alınan toprak örneklerinde makro besin elementlerinden kalsiyum ve magnezyum; mikro besin elementlerinden sodyum, demir, bakır, çinko ve mangan analiz edilmiştir. Kalsiyum, magnezyum ve sodyum amonyum asetat (ICP-OES) yöntemine göre, demir, bakır, çinko ve mangan TS ISO 14870 ICP-OES (DTPA) standardına göre yapılmıştır (Richards, 1954).

\section{3 İstatistik Analizler}

Analiz sonuçlarını değerlendirmek ve farklılıkları belirlemek amacıyla SPSS programında tek yönlü varyans analizi yapılmıştır. Farklı grupları belirlemek için Duncan testi uygulanmıştır. Ayrıca parametreler arasındaki ilişkileri belirlemek amacıyla Pearson korelasyon analizi yapılmıştır (SPSS, 2007).

\section{Bulgular ve Tartışma}

Çalışma alanında yangından bir ay sonra alınan toprak örneklerinde belirlenen makro ve mikro besin elementlerine ait ortalama değerler ve standart sapmalar Çizelge 1'de verilmiştir. 
Tablo 1. Toprak örneklerinden elde edilen makro ve mikro besin elementlerine ait ortalama değerler.

\begin{tabular}{llll}
\hline Bitki Besin Elementleri & Tarla & Yanmış Sekonder Mera & $\begin{array}{l}\text { Yanmamış Sekonder } \\
\text { Mera }\end{array}$ \\
\hline $\mathrm{Ca}(\mathrm{ppm})$ & $5843.3( \pm 98.6)^{\mathrm{a}}$ & $6938.8( \pm 306.5)^{\mathrm{b}}$ & $6400.6( \pm 159.4)^{\mathrm{c}}$ \\
$\mathrm{Mg}(\mathrm{ppm})$ & $116.8( \pm 5.9)^{\mathrm{a}}$ & $144.6( \pm 6.3)^{\mathrm{b}}$ & $174.5( \pm 7.2)^{\mathrm{c}}$ \\
$\mathrm{Na}(\mathrm{ppm})$ & $168.5( \pm 7.9)^{\mathrm{a}}$ & $166.1( \pm 7.9)^{\mathrm{a}}$ & $174.9( \pm 6.7)^{\mathrm{b}}$ \\
$\mathrm{Fe}(\mathrm{ppm})$ & $6.2( \pm 0.8)^{\mathrm{a}}$ & $6.8( \pm 0.4)^{\mathrm{a}}$ & $5.1( \pm 0.5)^{\mathrm{b}}$ \\
$\mathrm{Cu}(\mathrm{ppm})$ & $1.2( \pm 0.2)^{\mathrm{a}}$ & $1.2( \pm 0.1)^{\mathrm{a}}$ & $1.0( \pm 0.2)^{\mathrm{b}}$ \\
$\mathrm{Zn}(\mathrm{ppm})$ & $1.3( \pm 0.5)^{\mathrm{a}}$ & $1.5( \pm 0.5)^{\mathrm{a}}$ & $0.7( \pm 0.1)^{\mathrm{a}}$ \\
$\mathrm{Mn}(\mathrm{ppm})$ & $2.7( \pm 0.6)^{\mathrm{a}}$ & $8.0( \pm 2.2)^{\mathrm{b}}$ & $4.36( \pm 0.4)^{\mathrm{c}}$ \\
\hline
\end{tabular}

*Parantez içleri standart sapmaları göstermektedir. Farklı harfler ortalamalar arasında $(\mathrm{p}<0.05)$ fark olduğunu ifade etmektedir.

Tek yönlü varyans analizi sonuçlarına göre analiz edilen makro ve mikro besin elementlerine ait değerlerin ortalamaları; çinko hariç, çalışma alanlarına göre farklı bulunmuştur (Çizelge 1).

Makro besin elementlerinden olan kalsiyumun ortalama değerleri çalışma alanlarına göre farklı bulunmuştur. Farklılıkları belirlemek amacıyla yapılan Duncan testi sonuçlarına göre tarla alanı, yanmış sekonder mera alanı ve yanmamış sekonder mera alanı farklı gruplarda yer almıştır (Şekil 2).

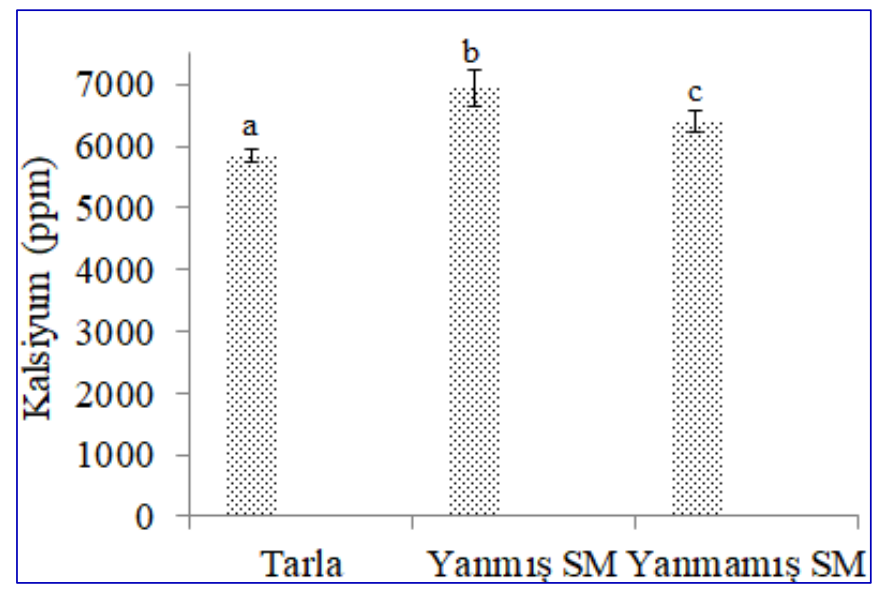

Şekil 2. Toprakların ortalama kalsiyum içeriklerinim araştırma alanlarına göre değişimi. Farklı harfler ortalamalar arasında farklılıklar olduğunu göstermektedir $(\mathrm{p}<0.05)$.

En yüksek değer 6938.8 ppm ile yanmış sekonder mera alanından elde edilmiştir. Bu durum yangının kalsiyum içeriğini artırdığını göstermektedir. Caldwell vd. (2002) tarafından yapılan bir çalışmada, yangın sonrasında kalsiyum içeriğinin azaldığı ancak istatistiki olarak bir anlam ifade etmediği bildirilmiştir. Başka çalışmalarda yangın sonrasında kalsiyum içeriğinin istatistiki anlamda yüksek bulunduğu ifade edilmiştir (Badía ve Martí, 2003; Pardini vd. 2004; Gómez-Rey vd., 2013). Bazı çalışmalarda ise; yangın sonrasında toprakların kalsiyum içeriklerinin istatistiki anlamda düşük bulunduğu belirtilmiştir (Kutiel ve Shaviv, 1992; Murphy vd. 2006b; Johnson vd. 2007; Kong vd., 2018). Bunun aksine İran'da (Norouzi ve Ramezanpour, 2013) ve Türkiye'de yapılan çalışmalarda (Parlak, 2018) yangından sonra toprakların kalsiyum içeriklerinin arttı̆ğ belirtilmiştir. Korelasyon analizi sonuçlarına göre; kalsiyum içerikleri ile magnezyum $(r=0.450)$ ve mangan $(r=0.690)$ arasında pozitif korelasyon bulunmuştur.

Makro besin elementlerinden olan magnezyumun ortalama değerleri çalışma alanlarına göre farklı bulunmuştur. Farklılıkları belirlemek amacıyla yapılan Duncan testi sonuçlarına göre tarla alanı, yanmış sekonder mera alanı ve yanmamış sekonder mera alanı farklı gruplarda yer almıştır (Şekil 3). 


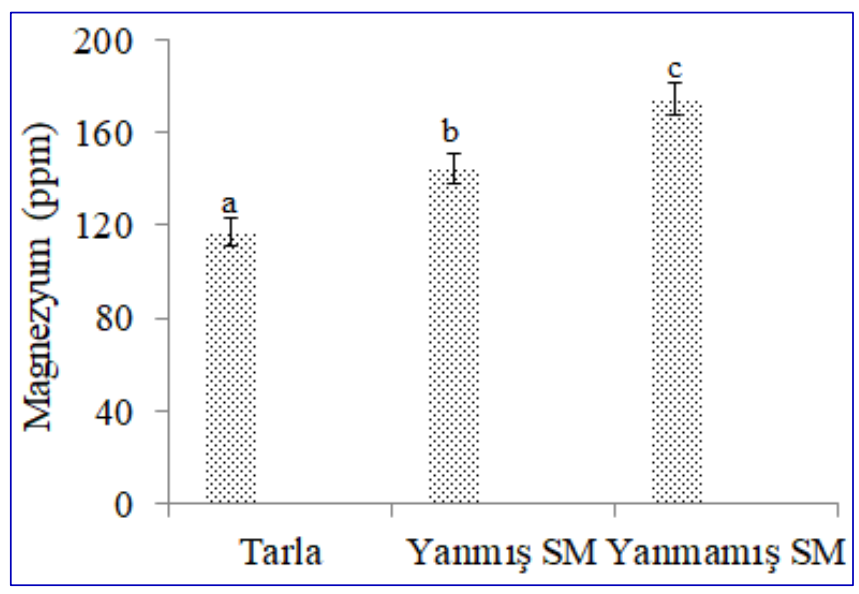

Şekil 3. Toprakların ortalama magnezyum içeriklerinim araştırma alanlarına göre değişimi. Farklı harfler ortalamalar arasında farklılıklar olduğunu göstermektedir $(\mathrm{p}<0.05)$.

En yüksek magnezyum içeriği 174.5 ppm ile yanmamış sekonder mera alanında bulunurken, en düşük magnezyum içeriği 116.8 ppm ile tarla alanında tespit edilmiştir. Yanmış sekonder mera alanında magnezyum içeriği 144.6 ppm olarak yanmamış alana göre daha düşük ve istatistiki anlamda farklı çıkmıştır. Bu durumda yangının magnezyum içeriğini azalttığı görülmektedir. Bazı çalışmalarda yangın sonrasında toprakların magnezyum içeriklerinin istatistiki anlamda düşük bulunduğu belirtilmiștir (Kutiel ve Shaviv, 1992; Johnson vd. 2007; Kong vd. 2018). Buna rağmen farklı çalışmalarda ise; yangın sonrası magnezyum içeriğinin arttığı belirtilmiştir (Brockway vd., 2002; Gómez-Rey vd., 2013). Badia vd. (2014) tarafından İspanya'da yapılan bir çalışmada; yangından bir hafta ve bir yıl sonra alınan toprak örneklerinde yanan alanda magnezyum içeriklerinin istatistiki anlamda artış gösterdiği belirtilmiştir. Korelasyon analizi sonuçlarına göre; magnezyum içerikleri ile kalsiyum $(r=0.450)$ ve sodyum $(r=0.526)$ arasında pozitif ancak demir $(r=-0.570)$ ve bakır $(r=-561)$ ile negatif korelasyon bulunmuştur.

Mikro besin elementlerinden sodyumun ortalama değerleri çalışma alanlarına göre farklı bulunmuştur. Farklılıkları belirlemek amacıyla yapılan Duncan testi sonuçlarına göre tarla alanı, yanmış sekonder mera alanı aynı grupta yer alırken yanmamış sekonder mera alanı farklı grupta yer almıştır (Şekil 4).

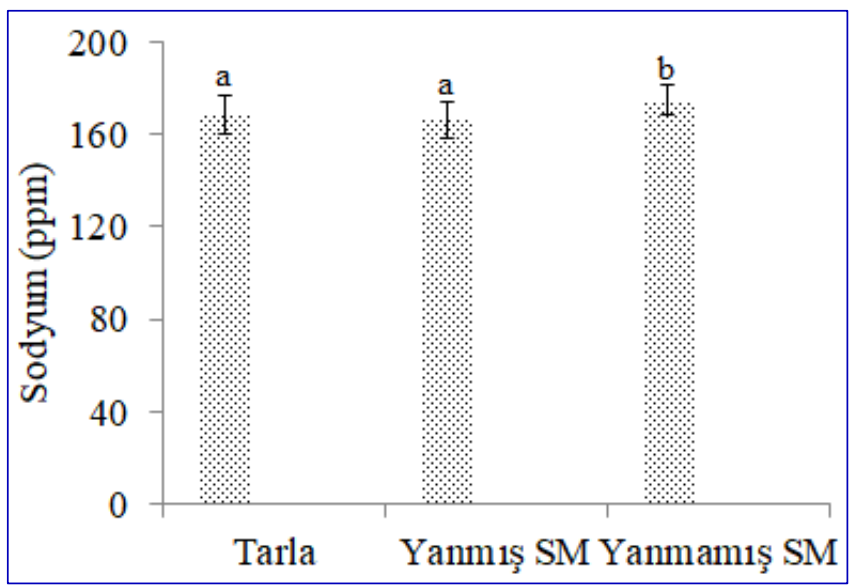

Şekil 4. Toprakların ortalama sodyum içeriklerinim araştırma alanlarına göre değişimi. Farklı harfler ortalamalar arasında farklılıklar olduğunu göstermektedir $(\mathrm{p}<0.05)$.

En yüksek ortalama sodyum değeri 174.9 ppm ile yanmamış sekonder mera alanında, en düşük değer ise 166.1 ppm ile yanmış sekonder mera alanında bulunmuştur. Tarla alanında ise 168.5 ppm belirlenmiştir. Böylece yangına bağlı olarak sodyum içeriğinin azaldığı tespit edilmiştir. Yangın sonrasında toprakların sodyum içeriklerinin düşük olduğu ancak istatistiki olarak anlamlı olmadığı belirtilmiştir (Kutiel ve Shaviv, 1992). Bazı çalışmalarda; yangın sonrası sodyum içeriğinin arttığ belirtilmiştir (Brockway vd., 2002; Gómez-Rey vd., 2013). Johnson vd. (2007) tarafından yapılan bir çalışmada yangın sonrasında toprakların sodyum içeriklerinin istatistiki anlamda düşük bulunduğu belirtilmiştir. Badia vd. (2014) tarafından İspanya'da yapılan bir çalışmada; yangından bir hafta ve bir 
yıl sonra alınan toprak örneklerinde sodyum içeriği yanmış sahalarda daha yüksek bulunmasına rağmen istatistiki anlamda bir fark bulunmamıştır. Başka bir çalışmada yangın sonrasında sodyum içeriğinin istatistiki anlamda yüksek bulunduğu ifade edilmiştir (Badía ve Martí, 2003). Korelasyon analizi sonuçlarına göre; sodyum içerikleri ile magnezyum $(r=0.526)$ arasında pozitif ancak demir $(r=-0.608)$, çinko $(r=-0.600)$ ve mangan $(r=-0.421)$ arasında negatif korelasyon bulunmuştur.

Mikro besin elementlerinden demirin ortalama değerleri çalışma alanlarına göre farklı bulunmuştur. Farklılıkları belirlemek amacıyla yapılan Duncan testi sonuçlarına göre, tarla ve yanmamış sekonder mera alanı aynı grupta yer alırken yanmış sekonder mera alanı farklı grupta yer almıştır (Şekil 5).

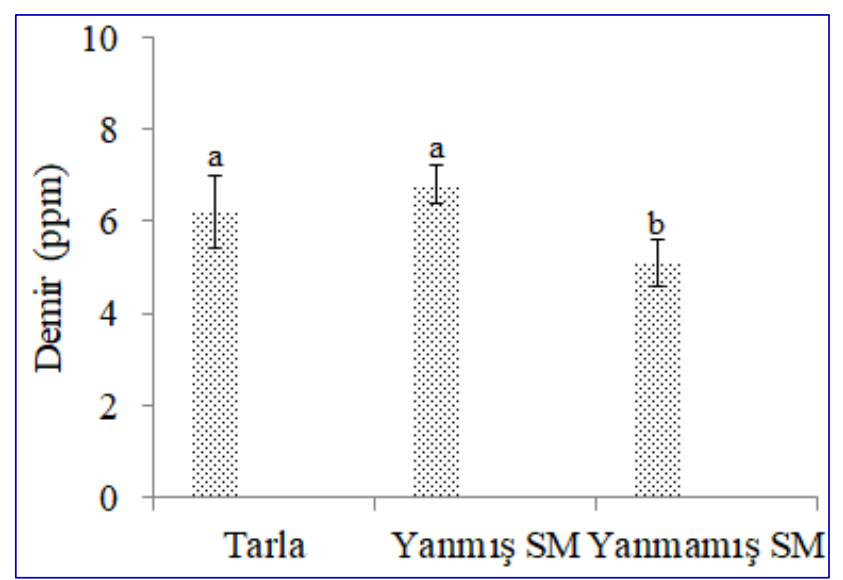

Şekil 5. Toprakların ortalama demir içeriklerinim araştırma alanlarına göre değişimi. Farklı harfler ortalamalar arasında farklılıklar olduğunu göstermektedir $(\mathrm{p}<0.05)$.

En yüksek ortalama değer 6.8 ppm ile yanmıș sekonder mera alanında, en düşük değer ise 5.1 ppm ile yanmamıș sekonder mera alanında bulunmuştur. Bu çalışmada, yangının demir içeriğini artırdığ 1 belirlenmiştir. Kong vd. (2018), yangından bir yıl ve onbir yıl sonra yapılan ölçümlerde, kontrol alanına kıyasla demir içeriklerinin artmış olduğu belirtilmiştir. Ayrıca, yangın sonrasında toprakların demir içeriklerinin arttığını ifade eden çalışmalar bulunmaktadır (Brais vd., 2000; Certini, 2005; Ponder vd., 2009; Campos vd., 2016). Ancak, yangından on y1l sonra yapılan bir araştırmada, yangın sahasında toprakların ortalama demir içerikleri yanmamış sahaya kıyasla istatistiki anlamda düşük bulunmuştur (Fernández-Fernández vd., 2015). Başka bir çalışmada, yangın sonrasında toprakların demir içeriklerinde istaistiki anlamda bir farklılık olmadığı belirtilmiştir (Gómez-Rey vd., 2013). Korelasyon analizi sonuçlarına göre; demir içerikleri ile bakır $(r=0.438)$ ve mangan $(r=0.424)$ arasında pozitif ancak magnezyum $(r=-0.570)$ ve sodyum $(r=-0.608)$ arasında negatif korelasyon bulunmuştur.

Mikro besin elementlerinden bakırın ortalama değerleri çalışma alanlarına göre farklı bulunmuştur. Farklılıkları belirlemek amacıyla yapılan Duncan testi sonuçlarına göre tarla alanı ve yanmış sekonder mera alanı aynı grupta yer alırken yanmamış sekonder mera alanı farklı grupta yer almıştır (Şekil 6).

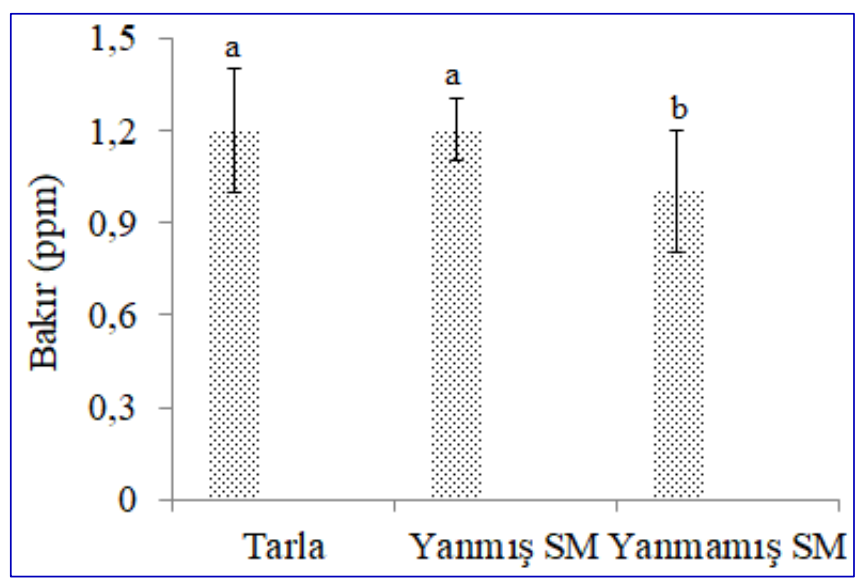

Şekil 6. Toprakların ortalama bakır içeriklerinim araştırma alanlarına göre değişimi. Farklı harfler ortalamalar arasında farklılıklar olduğunu göstermektedir $(\mathrm{p}<0.05)$. 
En yüksek ortalama değerler 1.2 ppm ile yanmış sekonder mera alanında ve tarla alanında, en düşük değer ise 1.0 ppm ile yanmamış sekonder mera alanında bulunmuştur. Bu çalışmada, yangının bakır içeriğini artırdığı belirlenmiştir. Benzer şekilde, yangın sonrasında toprakların bakır içeriğinin arttığı ifade eden araştırmalar bulunmaktadır (Brye vd., 2002; Jovanovic vd., 2011; Gómez-Rey vd. 2013). Ancak, yangından on yıl sonra yapılan bir araştırmada, yangın sahasında toprakların ortalama bakır içerikleri yanmamış sahaya kıyasla istatistiki anlamda farklı bulunmamıştır (Fernández-Fernández vd., 2015). Korelasyon analizi sonuçlarına göre; bakır içerikleri ile demir $(r=0.438)$ arasında pozitif ancak magnezyum $(r=-0.461)$ ile negatif korelasyon bulunmuştur.

Mikro besin elementlerinden çinkonun ortalama değerleri çalışma alanlarına göre farklı bulunmamıştır. Duncan testi sonuçlarına göre tüm çalışma alanları aynı grupta yer almıştır (Şekil 7).

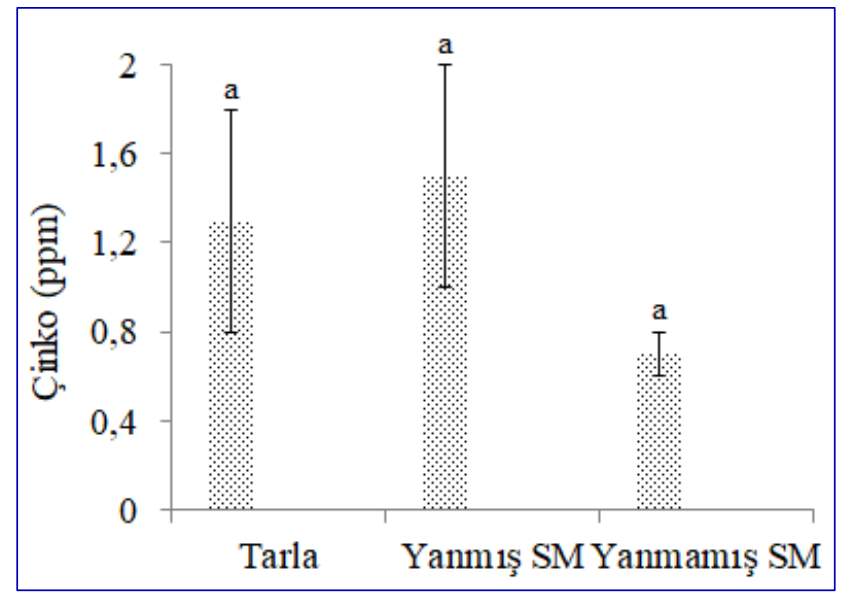

Şekil 7. Toprakların ortalama çinko içeriklerinim araştırma alanlarına göre değişimi. Farklı harfler ortalamalar arasında farklılıklar olduğunu göstermektedir $(\mathrm{p}<0.05)$.

Benzer şekilde, yangından on yıl sonra yapılan bir araştırmada, yangın sahasında toprakların ortalama çinko içerikleri yanmamış sahaya kıyasla istatistiki anlamda farklı bulunmamıştır (Fernández-Fernández vd., 2015). Yangın sonrasında toprakların çinko içeriğinin arttı̆̆ı ifade eden çalışmalar da bulunmaktadır (García-Marco ve González-Prieto, 2008; Pivello vd., 2010; Close vd., 2011; Jovanovic vd. 2011; Gómez-Rey vd., 2013). Ancak, yangından bir yıl ve onbir yıl sonra yapılan ölçümlerde, kontrol alanına kıyasla çinko içeriklerinin azalmış olduğu belirtilmiştir (Kong vd. 2018). Korelasyon analizi sonuçlarına göre; çinko içerikleri ile sodyum ( $r=-0.600)$ arasında negatif korelasyon bulunmuştur.

Mikro besin elementlerinden olan manganın ortalama değerleri çalışma alanlarına göre farklı bulunmuştur. Farklılıkları belirlemek amacıyla yapılan Duncan testi sonuçlarına göre tarla alanı, yanmış sekonder mera alanı ve yanmamış sekonder mera alanı farklı gruplarda yer almıştır (Şekil 8).

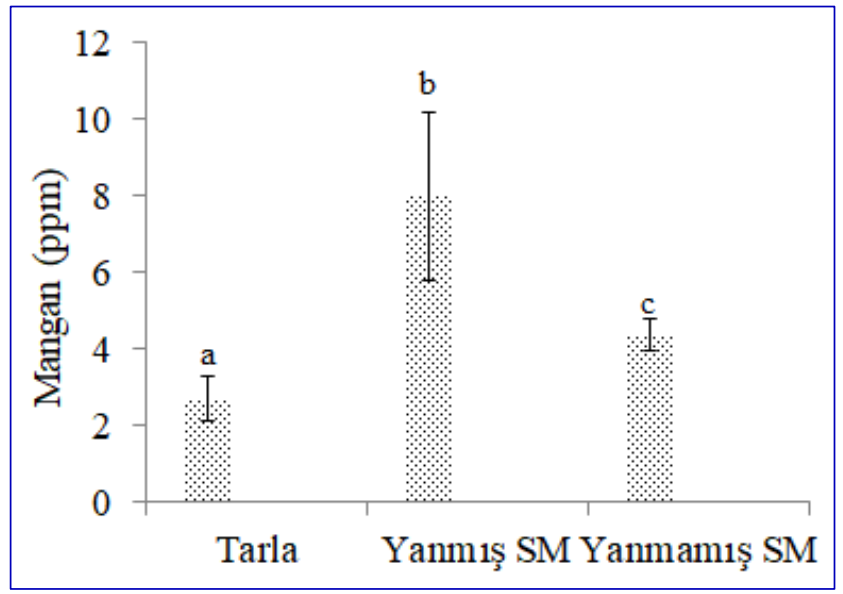

Şekil 8. Toprakların ortalama mangan içeriklerinim araştırma alanlarına göre değişimi. Farklı harfler ortalamalar arasında farklılıklar olduğunu göstermektedir $(\mathrm{p}<0.05)$. 
En yüksek değer 8.0 ppm ile yanmış sekonder mera alanından elde edilmiştir. En düşük değer ise 2.7 ppm ile tarla alanında bulunmuştur. Bu durum yangının mangan içeriğini artırdı̆̆ını göstermektedir. Yangından on yıl sonra yapılan bir araştırmada, yangın sahasında toprakların ortalama mangan içerikleri yanmamış sahaya kıyasla istatistiki anlamda farklı bulunmamışıtır (Fernández-Fernández vd., 2015). Başka çalışmalarda, yangın sonrasında toprakların çinko içeriklerinin arttığı belirtilmiştir (García-Marco ve González-Prieto, 2008; Pivello vd., 2010; Close vd., 2011; Gómez-Rey vd., 2013). Ancak, yangından bir yıl ve onbir yıl sonra yapılan ölçümlerde, kontrol alanına kıyasla mangan içeriklerinin azalmış olduğu belirtilmiştir (Kong vd. 2018). Korelasyon analizi sonuçlarına göre; mangan içerikleri ile kalsiyum $(r=0.690)$ ve demir $(r=0.424)$ arasında pozitif ancak sodyum $(r=-0.421)$ ile negatif korelasyon bulunmuştur.

\section{Sonuç ve Öneriler}

Yangının, toprakların besin elementlerini artırdığı veya azalttığı bilinmektedir. Bu çalışma, yangından bir ay sonra alınan toprak örnekleri analizlerine dayandığı için yangının besin elementleri üzerindeki kısa dönem etkilerini göstermektedir.

Çalışma sonuçlarına göre; yangının bazı besin elementleri üzerinde istatistiki anlamda farklılıklar oluşturduğu belirlenmiştir. Yangın sahasında, kalsiyum, demir, bakır ve mangan içeriklerinin yanmamış alana kıyasla artmış olduğu tespit edilmiştir. Yangının magnezyum ve sodyum içeriklerini istatistiki anlamda düşürdüğü bulunmuştur. Ancak, toprakların çinko içeriklerinde istatistiki anlamda bir fark bulunamamıştır. Yangının süresi, şiddeti, yoğunluğu ve üzerinden geçen zaman değiştikçe toprak özellikleri üzerindeki etkileri de değişmektedir. Bu nedenle, ilgili alanda yangından bir yıl sonra da toprak örnekleri alınarak bitki besin elementlerinin değişiminin incelenmesinin yararlı olacağı düşünülmektedir. Yangından sonraki ilk ayda, toprak üstünün çıplak olmasına ve yağışın yoğunluğuna bağlı olarak, yüzeysel akışın ve erozyonun artabileceği belirtilmiştir (Diaz-Fierros vd., 1987; Cerdà, 1998; Cerdà ve Lasanta, 2005; Vega vd., 2005). Bu nedenle, yangından sonra vejetasyon tamamen tahrip edilmişse acil olarak yangın sahasının yeniden bitkilendirme çalışmalarının yapılması bu süreç esnasında toprak kayıplarını engellemek amacıyla sahada malçlama yapılarak erozyona karşı tebirler alınması gerektiği belirtilmiştir (Cerdà ve Doerr, 2008). Yangın sahasının eğiminin yüksek olduğu (yaklaşık \%45) ve vejetasyonun büyük bölümünün yangından zarar gördügü göz önüne alındığında acilen gerekli tedbirler alınarak verimli toprağın kaybedilmesinin engellenmesi gerektiği düşünülmektedir. Bu tedbirlerin başında, yangın sahasının acilen bitkilendirilmesi gelmektedir. Bunun da en uygun yolunun üstten tohumlama yapmak olduğu düşünülmektedir.

\section{Kaynaklar}

1. Badía, D., Martí, C. (2003). Plant ash and heat intensity effects on chemical and physical properties of two contrasting soils. Arid Land Res. Manag. 17 (1): 23-41.

2. Badia, D., Marti, C., Aguirre, A.J., Aznar, J.M., Gonzalez-Perez, J.A., Rosa, J.M.D.L., Leon, J., Ibarra, P., Echeverria, T. (2014). Wildfire effects on nutrients and organic carbon of a Rendzic Phaeozem in NE Spain: Changes at cm-scale topsoil. Catena. 113: 267-275.

3. Bolat, İ., Kara, Ö., Tunay, M. (2020). Göknar-Kayın Karışık Meşceresi Altındaki Ölü Örtü Örneklerinde Mikrobiyal Biyokütle C (Cmic), N (Nmic) ve P (Pmic)'un Mevsimsel Değişimi. Bartın Orman Fakültesi Dergisi. 22 (3): 1-1.

4. Brais, S., David, P., Ouimet, R. (2000). Impact of wildfire severity and salvage harvesting on the nutrient balance of jack pine and black spruce boreal stands. For. Ecol. Manag. 137 (1-3): 231-243.

5. Brockway, D.G., Gatewood, R.G., Paris, R.B. (2002). Restoring fire as an ecological process in shortgrass prairie ecosystems: initial effects of prescribed burning during the dormant and growing seasons. J. Environ. Manag. 65 (2): 135-152.

6. Brye, K.R., Norman, J.M., Gower, S.T. (2002). The fate of nutrients following three- and six-year burn intervals in a tallgrass prairie restoration in Wisconsin. The American Midland Naturalist. 148 (1), 28-42.

7. Caldwell, T.G., Johnson, D.W., Miller, W.W., Qualls, R.G. (2002). Forest floor carbon and nitrogen losses due to prescription fire. Soil Sci. Soc. Am. J. 66 (1): 262-267.

8. Campos, I., Abrantes, N., Keizer, J.J., Val, C., Pereira, P. (2016). Major and trace elements in soils and ashes of eucalypt and pine forest plantations in Portugal following a wildfire. Sci. Total Environ. 572: 13631376.

9. Caon, L., Vallejo, V.R., Ritsema, C.J., Geissen, V. (2014). Effects of wildfire on soil nutrients in Mediterranean ecosytems. EarthScience Reviews 139: 47-58. 
10. Carballas, M., Acea, M.J., Cabaneiro, C., Trasar, C., Villar, M.C., Diaz-Ravina, M., Fernandez, I., Prieto, A., Saa, A., Vazquez, F.J., Zehner, R., Carballas, T. (1993). Organic matter, nitrogen, phosphorus and microbial population evolution in forest humiferous acid soils after wildfires. In: Trabaud, L., Prodon, R. (Eds.), Fire in Mediterranean Ecosystems. Ecosystems Research Report 5. Commission of the European Communities, pp. 379-385.

11. Cerdà, A. (1998). Postfire dynamics of erosional processes under mediterranean climatic conditions. Zeitschrift für Geomorphologie. 42 (3): 373-398.

12. Cerdà, A., Doerr, S.H. (2008). The effect of ash and needle cover on surface runoff and erosion in the immediate post-fire period. Catena. 74 (3): 256-263.

13. Cerdà, A., Lasanta, T. (2005). Long-term erosional responses after fire in the Central Spanish Pyrenees 1. Water and sediment yield. Catena. 60 (1), 59-80.

14. Certini, G. (2005). Effects of fire on properties of forest soils: a review. Oecologia 143 (1), 1-10.

15. Chandler, C., Cheney, P., Thomas, P., Trabaud, L., Williams, D. (Eds.) (1983). Fire in forestry. In: Forest Fire Behaviour and Effects, vol. I. Wiley, New York, pp. 171-202.

16. Close, D., Davidson, N., Swanborough, P., Corkrey, R. (2011). Does low-intensity surface fire increase water- and nutrient-availability to overstorey Eucalyptus gomphocephala? Plant and Soil 349 (1): $203-214$.

17. Diaz-Fierros, F., Benito Rueda, E., Perez Moreira, R. (1987). Evaluation of the U.S.L.E. for the prediction of erosion in burnt forest areas in Galici (NW Spain). Catena 14 (1-3): 189-199.

18. Diaz-Fierros, F., Benito, E., Vega, J.A., Castelao, A., Soto, B., Perez, R., Taboada, T. (1989). Solute loss and soil erosion in burnt soil from Galicia, N.W. Spain. In: Goldammer, J.G., Jenkins, M.J. (Eds.), Fire in Ecosystem Dynamics: Mediterranean and Northern Perspectives. S.P.B. Academic Publishing, The Hague, pp. 103-116.

19. Fang, L., Yang, J., Zu, J., Li, G., Zhang, J. (2015). Quantifying influences and relative importance of fire weather, topography, and vegetation on fire size and fire severity in a Chinese boreal forest landscape. For. Ecol. Manag. 356: 2-12.

20. Fernandez, C., Vega, J.A., Fonturbel, T., Pe'rez, P.G., Jiménez, E., Madrigal, J. (2007). Effects of wildfire, salvage logging and slash treatments on soil degradation. Land Degrad. Dev. 18 (6): 591-607.

21. Fernández-Fernández, M., Gómez-Rey, M.X., González-Prieto, S.J. (2015). Effects of fire and three firefighting chemicals on main soil properties, plant nutrient content and vegetation growth and cover after 10 years. Science of the Total Environment, 515-516: 92-100.

22. García-Marco, S., González-Prieto, S. (2008). Short- and medium-term effects of fire and fire-fighting chemicals on soil micronutrient availability. The Science of the Total Environment 407 (1): 297-303.

23. Griffiths, R.P., Madritch, M.D., Swanson, A.K. (2009). The effects of topography on forest soil characteristics in the Oregon Cascade Mountains (USA): implications for the effects of climate change on soil properties. For. Ecol. Manag. 257 (1): 1-7.

24. Gómez-Rey, M.X., Couto-Vázquez, A., García-Marco, S., González-Prieto, S.J. (2013). Impact of fire and post-fire management techniques on soil chemical properties. Geoderma, 195-196: 155-164.

25. Guerrero, C., Gómez, I., Moral, R., Mataix-Solera, J., Mataix-Beneyto, J., Hernández, T. (2001). Reclamation of a burned forest soil with municipal waste compost: macronutrient dynamic and improved vegetation cover recovery. Bioresource Technology, 76 (3): 221-227.

26. Hernández, T., Garcia, C., Reinhardt, I. (1997). Short-term effect of wildfire on the chemical, biochemical and microbiological properties of Mediterranean pine forest soils. Biology and fertility of soils, 25 (2): 109116.

27. Jovanovic, V.S., Ilic, M.D., Markovic, M.S., Mitic, V.D., Mandic, S.N., Stojanovic, G.S. (2011). Wild fire impact on copper, zinc, lead and cadmium distribution in soil and relation with abundance in selected plants of Lamiaceae family from Vidlic Mountain (Serbia). Chemosphere, 84 (11): 1584-1591.

28. Johnson, D., Murphy, J.D., Walker, R.F., Glass, D.W., Miller, W.W. (2007). Wildfire effects onforest carbon and nutrient budgets. Ecol. Eng. 31 (3): 183-192.

29. Kara, O., Bolat, I. (2009). Short-term effects of wildfire on microbial biomass and abundance in black pine plantation soils in Turkey. Ecological Indicators, 9 (6): 1151-1155.

30. Kennard, D.K., Gholz, H.L. (2001). Effects of high- and low-intensity fires on soil properties and plant growth in a Bolivian dry forest. Plant and Soil. 234 (1): 119-129.

31. Kong, J.J., Yang, J., Bai, E. (2018). Long-term effects of wildfire on available soil nutrient composition and stoichiometry in a Chinese boreal forest. Science of the total environment, 642: 1353-1361.

32. Kutiel, P., Shaviv, A. (1989). Changes of soil N-P status in laboratory simulated forest fire. Plant and Soil 120: 57-63.

33. Kutiel, P., Shaviv, A. (1992). Effects of soil type. Plant composition and leaching on soil nutrients following a simulated forest-fire. For. Ecol. Manag. 53 (1-4): 329-343.

34. Parlak, M. (2018). Çanakkale (Eceabat, Akbaş Şehitliği) orman yangınıyla bazı fiziksel ve kimyasal toprak özelliklerinin zamansal değişiminin belirlenmesi. Toprak Bilimi ve Bitki Besleme Dergisi, 6 (1): 29-38. 
35. Pivello, V.R., Oliveras, I., Miranda, H.S., Haridasan, M., Sato, M.N., Meirelles, S.T. (2010). Effect of fires on soil nutrient availability in an open savanna in Central Brazil. Plant and Soil. 337 (1): 111-123.

36. Murphy, J.D., Johnson, D.W., Miller, W.W., Walker, R.F., Carroll, E.F., Blank, R.R. (2006a). Wildfire effects on soil nutrients and leaching in a tahoe basin watershed. J. Environ. Qual. 35 (2): 479-489.

37. Murphy, J.D., Johnson, D.W., Miller, W.W., Walker, R.F., Blank, R.R. (2006b). Prescribed fire effects on forest floor and soil nutrients in a Sierra Nevada forest. Soil Sci. 171 (3): 181-199.

38. Neary, D.G., Ryan, K.C., DeBano, L.F. (2005). Wildland Fire in Ecosystems: Effects of Fire on Soil and Water. Gen. Tech. Rep. RMRS-GTR-42-vol.4. U.S. Department of Agriculture, Forest Service, Rocky Mountain Research Station, Ogden, UT, 250 p.

39. Norouzi, M., Ramezanpour, H. (2013). Effect of fire on soil nutrient availability in forestes of Gulian, North of Iran. Carpathian Journal of Earth and Environmental Sciences 8(1): 157-170.

40. Pardini, G., Gispert, M., Dunj, G. (2004). Relative influence of wildfire on soil properties and erosion processes in different Mediterranean environments in NE Spain. Sci. Total Environ. 328 (1-3): 237-246.

41. Ponder, F., Tadros, M., Loewenstein, E.F. (2009). Microbial properties and litter and soil nutrients after two prescribed fires in developing savannas in an upland Missouri Ozark Forest. Forest Ecology and Management 257 (2): 755-763.

42. Richards, L.A. (1954). Diagnosis and improvement of saline and alkali soils (Vol. 78, No. 2, p. 154). LWW.

43. SPSS (2007). SPSS for Windows, Version 16.0. Chicago: SPSS Inc.

44. St Jhon, T.V., Rundel, P.W. (1976). The role of fire as a mineralizing agent in a Sierran Coniferous Forest. Oecologia 25 (1): 35-45.

45. Turner, M.G., Romme, W.H., Smithwick, E.A.H., Tinker, D.B., Zhu, J. (2011). Variation in aboveground cover influences soil nitrogen availability at fine spatial scales following severe fire in subalpine conifer forests. Ecosystems. 14 (7): 1081-1095.

46. White, E.M., Thompson, W.W., Gartner, F.R. (1973). Heat effects on nutrient release from soils under Ponderosa Pine. J. Range Manag. 26 (1): 22-24.

47. Vazquez, F.J., Acea, M.J., Carballas, T. (1993). Soil microbial populations after wildfire. FEMS Microb. Ecol. 13, 93-104.

48. Vazquez, F.J., Petrikova, V., Villar, M.C., Carballas, T. (1996). Use of poultry manure and plant cultivation for the reclamation of burnt soils. Biol. Fertil. Soils. 22 (3): 265-271.

49. Vega, J.A., Fernandez, C., Fonturbel, T. (2005). Throughfall, runoff and soil erosion after prescribed burning in gorse shrubland in Galicia (NW Spain). Land Degradation and Development. 16 (1): 37-51. 